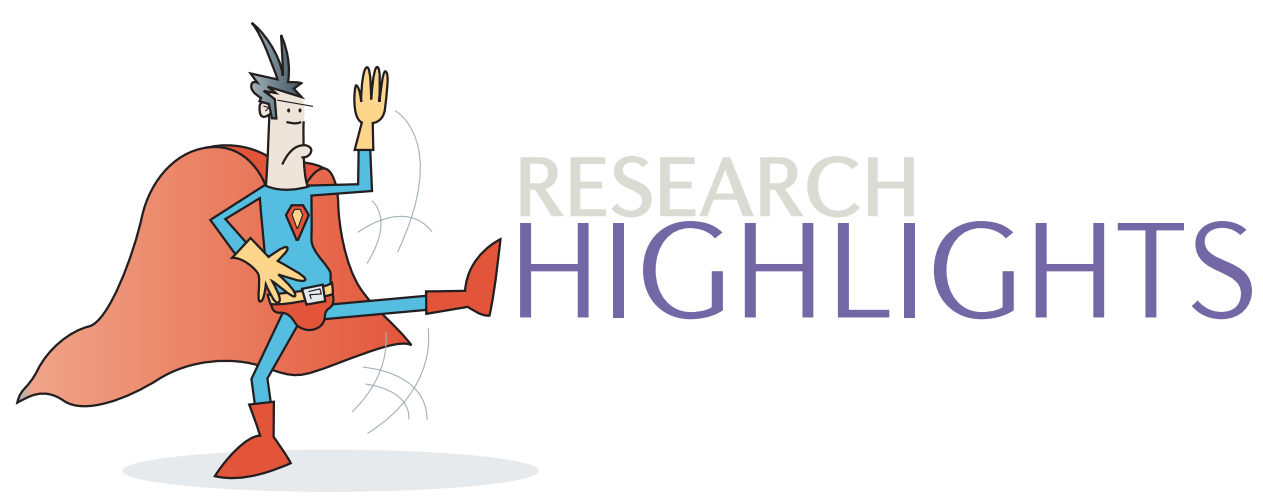

(2) IMMUNOTHERAPY

\section{Cortistatin to the rescue}

The quest to find specific, effective and safe therapeutic agents for inflammatory disorders such as Crohn's disease and septic shock is an ongoing struggle. Now, two new studies by Gonzalez-Rey et al. describe a recently discovered endogenous factor, cortistatin, as an effective anti-inflammatory factor and a potential multistep therapeutic agent for inflammatory disorders.

Cortistatin is related to the cyclic neuropeptide somatostatin, which has been shown to have immunomodulatory properties. Administration of cortistatin 12 hours after induction of colitis using 2,4,6-trinitrobenzene sulphonic acid (TNBS) in mice - which is a model similar to human Crohn's disease in its clinical, pathological and immunological features - protected mice against colitis development. Administration of cortistatin to TNBS-treated mice ameliorated the associated histopathology and clinical symptoms of TNBS-induced colitis, includintestinal inflammation and mortality. Interestingly, treatment with cortistatin 6 days after TNBS administration abrogated ongoing disease and ing weight loss, diarrhoea, was also effective at reducing disease recurrence.

Analysis of the inflammatory mediators in the colon showed a substantial reduction in the production of various pro-inflammatory cytokines and chemokines in mice treated with cortistatin. Decreased in the colonic mucosa was also observed. However, it would seem that the decrease in cytokine and chemokine production was not a result of reduced numbers of infiltrating cells but of direct suppression of lamina-propria mononuclear cells. In addition, $\mathrm{CD} 4^{+}$ $\mathrm{T}$ cells isolated from cortistatintreated mice with colitis produced less interferon- $\gamma($ IFN $\gamma$ ) than $\mathrm{T}$ cells from untreated mice with colitis. infiltration of inflammatory cells

of IL-10-producing cells was increased. This observation indicates that cortistatin induces the generation and/or activation of IL-10-producing $\mathrm{T}$ cells that might contribute to the observed protection against colitis development.

In a separate study, this group also showed a protective role for cortistatin in a model of septic shock. Administration of cortistatin protected mice against endotoxininduced lethality and associated histopathology. These effects seem to be mediated through the suppression of pro-inflammatory cytokine, chemokine and acutephase protein production. Cortistatin treatment was also associated with increased IL-10 production in this model.

These data indicate that cortistatin is a potent anti-inflammatory agent that suppresses the production of pro-inflammatory mediators while increasing IL-10 production in two different disease models. Therefore, the authors suggest that cortistatin might represent a potential therapeutic agent for Crohn's disease and septic shock.

Olive Leavy

\section{ORIGINAL RESEARCH PAPERS}

Gonzalez-Rey, E. et al. Cortistatin, an antiinflammatory peptide with therapeutic action in inflammatory bowel disease. Proc. Natl Acad. Sci. USA 103, 4228-4233 (2006) Gonzalez-Rey, E. et al. Cortistatin, a new antiinflammatory peptide with therapeutic effect on lethal endotoxemia. J. Exp. Med. 203, 563-571 (2006)

FURTHER READING Greenwood, J., Steinman, L. \& Zamvil. S. S. Statin therapy and autoimmune disease: from protein prenylation to immunomodulation. Nature Rev. Immunol.

6, 358-370 (2006)

\section{RESEARCH HIGHLIGHTS ADVISORS}

CEZMI AKDIS Swiss Institute of Allergy and Asthma Research, Davos, Switzerland BRUCE BEUTLER

The Scripps Research Institute, La Jolla, USA PETER CRESSWEL

PETER CRESSWELL
Yale University, New Haven, USA
JAMES DI SANTO

Institut Pasteur, Paris, France GARY KORETZKY University of Pennsylvania, Philadelphia, USA CHARLES MACKAY Garvan Institute of Medical Research, Sydney, Australia
CORNELIS MELIEF

Leiden University Medical Center Leiden, The Netherlands MICHEL NUSSENZWEIG The Rockefeller University, New York, USA RICHARD RANSOHOFF

The Cleveland Clinic Foundation, Cleveland, USA
ALAN SHER

National Institute of Allergy and Infectious Diseases, Bethesda, USA ANDREAS STRASSER The Walter and Eliza Hall Institute of Medical Research, Melbourne, Australia
MEGAN SYKES

Harvard Medical School, Boston, USA ERIC VIVIER

Centre d'Immunologie de MarseilleLuminy, Marseille, France MATTHIAS VON HERRATH

La Jolla Institute for Allergy and Immunology, San Diego, USA 